\title{
Gonadotrope androgen receptor mediates pituitary responsiveness to hormones and androgen-induced subfertility
}

\author{
Zhiqiang Wang, ${ }^{1}$ Mingxiao Feng, ${ }^{1}$ Olubusayo Awe, ${ }^{1}$ Yaping Ma, ${ }^{1,2}$ Mingjie Shen, ${ }^{1,3}$ Ping Xue, ${ }^{1}$ \\ Rexford Ahima, ${ }^{4}$ Andrew Wolfe, ${ }^{1,5}$ James Segars, ${ }^{6}$ and Sheng Wu $\mathbf{u}^{1,5,6}$ \\ 'Department of Pediatrics, Johns Hopkins University School of Medicine, Baltimore, Maryland, USA. ${ }^{2}$ Department of \\ Pediatrics, Affiliated Hospital of Jiangnan University, Wuxi, China. ${ }^{3}$ Department of Gynecology and Obstetrics, Shuguang \\ Hospital Affiliated with Shanghai University of Traditional Chinese Medicine, Shanghai, China. ${ }^{4}$ Department of Medicine, \\ ${ }^{5}$ Department of Molecular and Cellular Physiology, and ${ }^{6}$ Department of Gynecology and Obstetrics, Johns Hopkins \\ University School of Medicine, Baltimore, Maryland, USA.
}

\begin{abstract}
Many women with hyperandrogenemia suffer from irregular menses and infertility. However, it is unknown whether androgens directly affect reproduction. Since animal models of hyperandrogenemia-induced infertility are associated with obesity, which may impact reproductive function, we have created a lean mouse model of elevated androgen levels using implantation of low-dose $5 \alpha$-dihydrotestosterone (DHT) pellets to separate the effects of elevated androgen levels from obesity. The hypothalamic-pituitary-gonadal axis controls reproduction. While we have demonstrated that androgens impair ovarian function, androgens could also disrupt neuroendocrine function at the level of brain and/or pituitary to cause infertility. To understand how elevated androgen levels might act on pituitary gonadotropes to influence reproductive function, female mice with disruption of the androgen receptor (Ar) gene specifically in pituitary gonadotropes (PitARKO) were produced. DHT-treated control mice with intact pituitary Ar (ConDHT) exhibited disrupted estrous cyclicity and fertility with reduced pituitary responsiveness to gonadotropin-releasing hormone ( $\mathrm{GnRH}$ ) at the level of both calcium signaling and luteinizing hormone (LH) secretion. These effects were ameliorated in DHT-treated PitARKO mice. Calcium signaling controls $\mathrm{GnRH}$ regulation of $\mathrm{LH}$ vesicle exotocysis. Our data implicate upregulation of GEM (a voltage-dependent calcium channel inhibitor) in the pituitary as a potential mechanism for the pathological effects of androgens. These results demonstrate that gonadotrope AR, as an extraovarian regulator, plays an important role in reproductive pathophysiology.
\end{abstract}

Conflict of interest: The authors have declared that no conflict of interest exists

Copyright: () 2019 American Society for Clinical Investigation

Submitted: January 29, 2019

Accepted: August 6, 2019

Published: August 8, 2019.

Reference information: /CI Insight. 2019;4(17):e127817. https://doi. org/10.1172/jci.insight.127817.

\section{Introduction}

Hyperandrogenemia is a salient feature in many women who suffer irregular menses, oligo/anovulation, and infertility, including women with polycystic ovary syndrome (PCOS) (1), classic and nonclassic (late-onset) congenital adrenal hyperplasia (CAH) (2-5), exogenous testosterone treatment in female to male transsexuals (6-10), exogenous androgen use (body builders), or environmental toxicity (11). Although each of these conditions feature androgen excess, in some cases (e.g., PCOS), it is not clear whether increased androgen levels are a consequence of reproductive pathology or directly contribute to the progression of reproductive pathology.

Several models have been developed in rodents and other animals to probe the effects of androgens on the reproductive axis $(4,12-17)$. These models showed reproductive dysfunction but were also associated with obesity. This is problematic because obese female rodents and women have higher circulating testosterone levels and impaired fertility (18-20). Consequently, it is not possible to determine whether the phenotype is caused by the androgen excess or obesity. To address this problem, we created an adult mouse model (21-23) that develops reproductive and metabolic dysfunction within 2 weeks after chronic $5 \alpha$-dihydrotestosterone (DHT) exposure from a pellet containing DHT (2xDHT mice). This model produces serum DHT levels in mice that are 2-fold higher than in controls. Importantly, the mildly elevated levels resemble the 1.5- to 3.9-fold elevation of testosterone and DHT in 


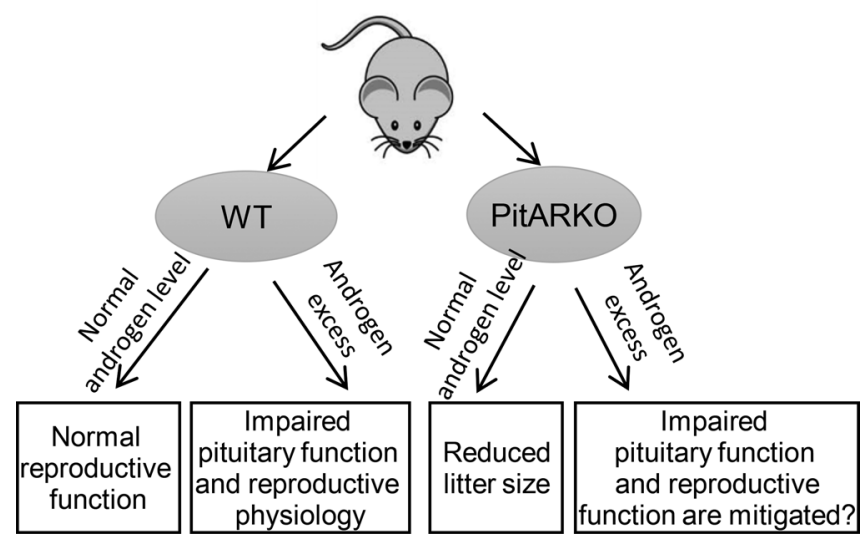

Figure 1. Overview of mouse models used in this study to elucidate the role of AR in gonadotropes in androgen excess.

women with PCOS $(4,24-30)$. Notably, the $2 x D H T$ mice do not exhibit alterations of basal serum estradiol, testosterone, or luteinizing hormone ( $\mathrm{LH})$; do not develop obesity; and show similar ovarian weight, serum levels of cholesterol, free fatty acids, leptin, TNF $\alpha$, and IL-6 relative to controls even up to 3.5 months after DHT insertion $(21,22,31)$.

Due to the interconnected nature of the hypothalamic-pituitary-gonadal axis, effects of excess androgens could be exerted at multiple levels of the axis $(22,32)$. While some androgen effects occur in the brain, as reported by others $(32,33)$, whether ARs in gonadotropes contribute to the dysregulation of female estrous cycles and gonadotropin secretion is unknown. To define how androgen/AR in the pituitary contributes to reproductive dysfunction, and the molecular mechanisms that are underlying the pathophysiology, we used the $2 \mathrm{xDHT}$ mouse model with intact (Control; $\mathrm{AR}^{\mathrm{A} / \mathrm{fl}}, \mathrm{Cre}^{-}$) or disrupted $\mathrm{AR}$ in gonadotropes (PitARKO; $\mathrm{AR}^{\mathrm{f} / / \mathrm{l}}, \mathrm{Cre}^{+/-}$) (34) to probe the role of $\mathrm{AR}$ in gonadotrope cells (Figure 1). Since pituitary responsiveness to gonadotropin-releasing hormone $(\mathrm{GnRH})$ stimulation is disrupted by high androgen levels (35) in vitro, and because GnRH-mediated increases in cytosolic $\mathrm{Ca}^{2+}$ are crucial for exocytosis of LH granules $(36,37)$, we studied GEM, a GTP-binding protein that binds calmodulin to reduce $\mathrm{Ca}^{2+}$ influx (36-38). Our findings demonstrate important roles for gonadotropic AR in reproduction as an extraovarian regulatory factor. Gonadotropic AR-mediated reproductive dysfunction may act through GEM, reducing LH secretion from the pituitary in the presence of DHT.

\section{Results}

DHT disrupts estrous cyclicity in control but reserved in PitARKO mice. To explore the role of pituitary AR in hyperandrogenic-induced abnormal cyclicity, we analyzed 4 groups of mice (control-no DHT [Con-no DHT], Con-DHT, PitARKO-no DHT, and PitARKO-DHT). Since PitARKO mice bore a reduced number of pups compared with control littermates under normal androgen conditions (34), we compared reproductive physiology in mice with the same genotype as described (32). As expected, we observed that Con-DHT mice spent significantly less time in proestrus and estrus phases and more time in diestrus and metestrus than Con-no DHT mice (Figure 2, A and B). The time in proestrus of PitARKO-DHT mice was approximately $70 \%$ compared with Con-no DHT mice, without a significant reduction compared with PitARKO-no DHT. In PitARKO-DHT mice, estrous cyclicity was virtually indistinguishable from PitARKO-no DHT mice.

Androgen-induced fertility impairment was reduced in PitARKO mice. Pups and litters per dam were recorded during 90 days of mating and displayed as a fertility plot (for brevity, only fertility plots from PitARKO-DHT and Con-DHT groups are shown; Figure 3A). Fertility data from all 4 groups were further analyzed to assess total number of litters and pups per female. The number of litters (Figure 3B) and pups per female (Figure 3C) were both significantly reduced in control mice treated with DHT (Con-DHT vs. Con-no DHT). While the number of litters from PitARKO-DHT mice was reduced when compared to Con-no DHT mice, the reduction in litter size was greater than the reduction in litter size of PitARKO-no DHT mice. Also, the number of pups was reduced when compared with Con-no DHT, but the reduction was not significant compared with PitARKO-no DHT mice. Importantly, the number of litters and pups was significantly higher 


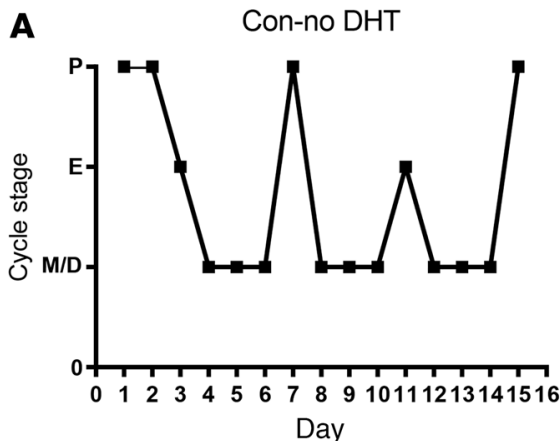

Con-DHT

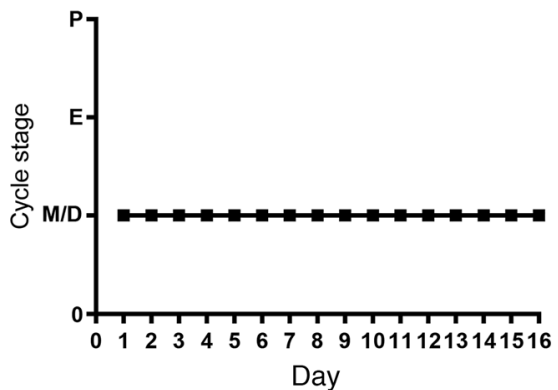

B

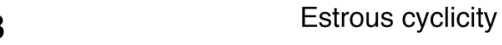

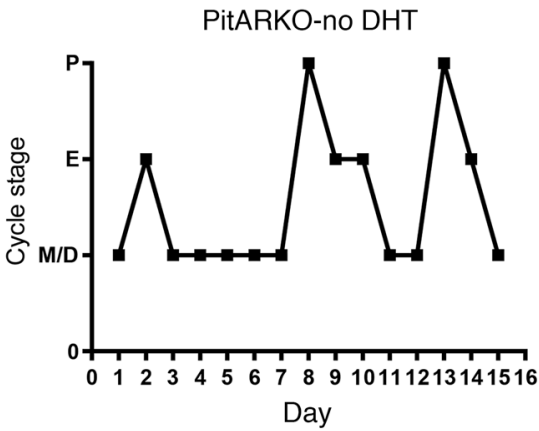

PitARKO-DHT

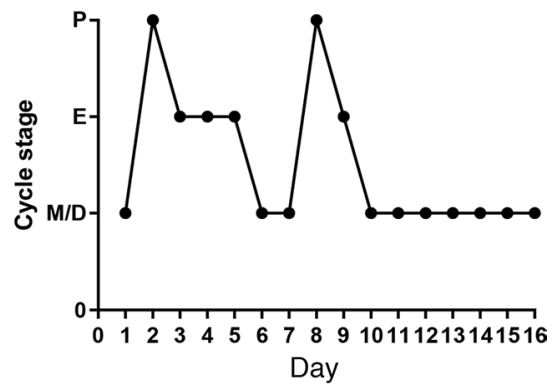

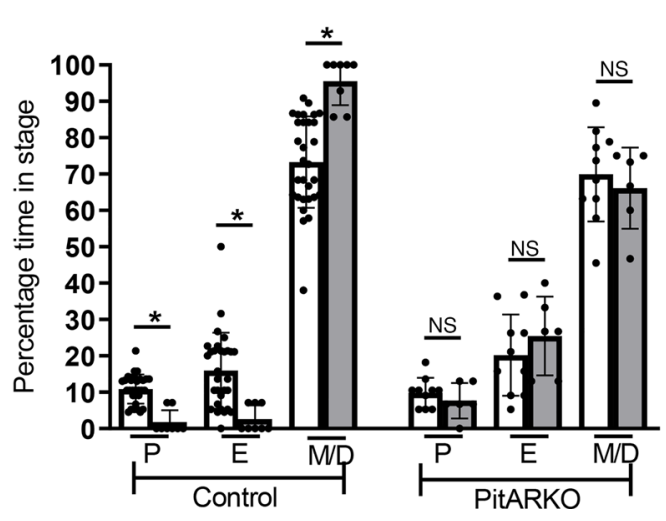

Figure 2. Estrous cyclicity. Murine estrous cyclicity was examined by vaginal smear. (A) The examples of estrous cyclicity in each group. P, proestrus; E, estrus; M/D, Metestrus/Diestrus. (B) The percentage time in each stage was calculated by the total days of each estrous stage divided by the total 16 days. $n=6-30$. Data were compared by 2 -tailed Student's $t$ test. ${ }^{*} P<0.05$.

in PitARKO-DHT mice compared with Con-DHT mice (Figure 3, B and C), which suggests that $A r$-KO in gonadotropes partially mitigated the impairment in fertility caused by androgens. As we have previously reported, under normal androgen levels, PitARKO mice have a similar number of litters compared with control mice, while the number of pups was significantly reduced (Figure 3 and ref. 34).

Androgen-induced disruption of ovulation was mitigated in hyperandrogenic mice lacking gonadotropic AR. Morphology of representative ovaries from Con-no DHT, Con-DHT, PitARKO-no DHT, and PitARKO-DHT mice is shown in Figures 3, D-G. A marked difference was shown in abundance of corpora lutea (CLs) that serves as an anatomical marker of recent ovulation. CLs were much less common in the ovaries of the Con-DHT mice than in any of the other 3 groups (Figure 3, D-H). Con-DHT ovaries had significantly fewer CLs compared with ovaries from Con-no DHT mice. However, the number of CLs in PitARKO-DHT ovaries were not significantly different from ovaries from PitARKO-no DHT females.

Pituitary responsiveness to GnRH stimulation was preserved in PitARKO-DHT mice. To investigate the effects of DHT on pituitary responses to GnRH, control and PitARKO female mice, with or without DHT, were stimulated 
A
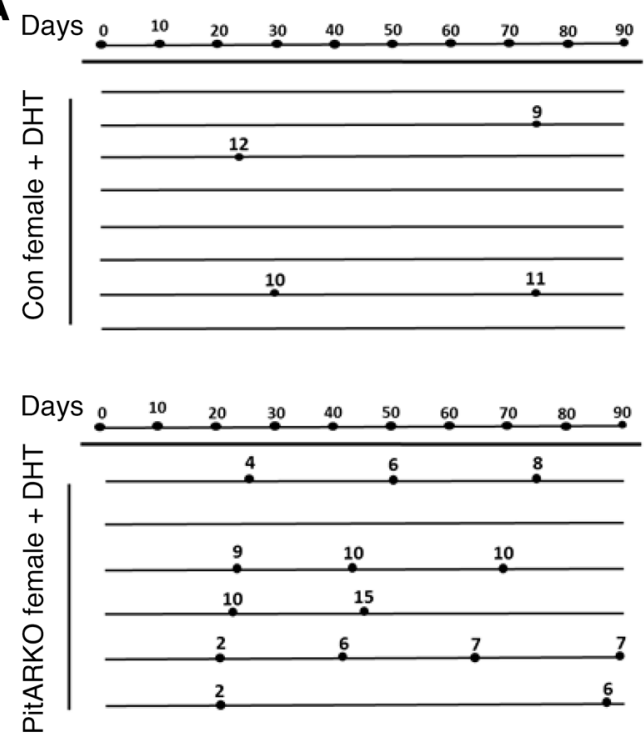

D

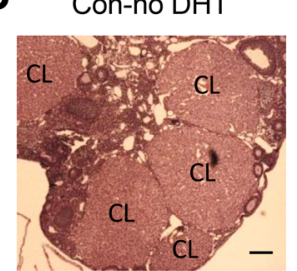

$\mathbf{F}$

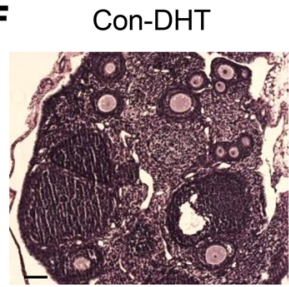

E PitARKO-no DHT

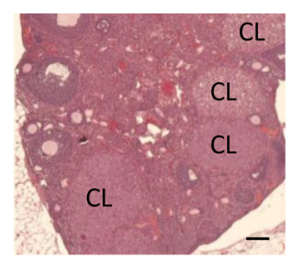

G PitARKO-DHT

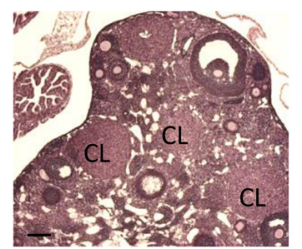

B

Litters

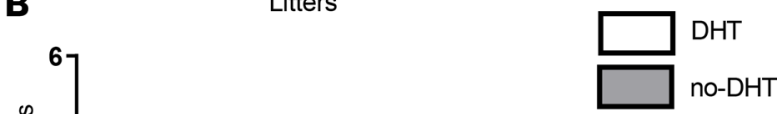

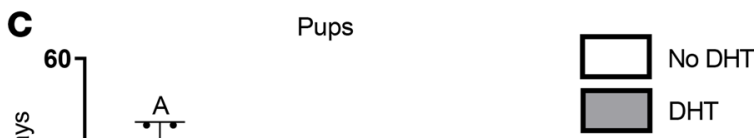

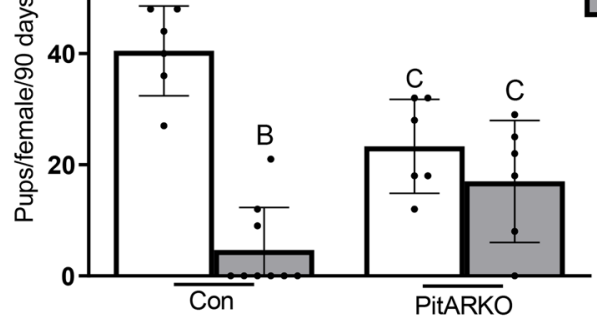

H

$\mathrm{CL}$

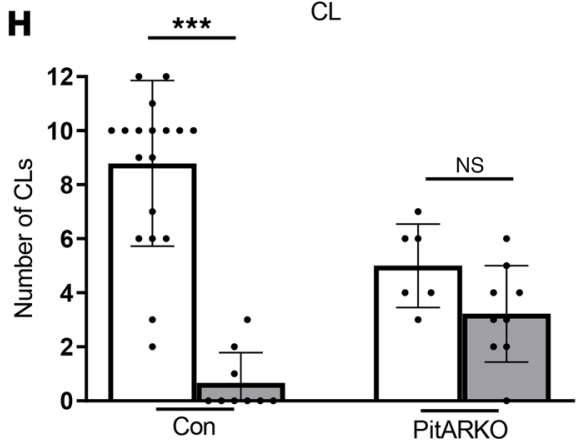

Figure 3. Fertility assessment. (A) Female mice were mated with proven fertile male mice for 90 days, and the number of litters and pups were recorded. Plots of mating outcomes for Con-DHT (top) and PitARKO-DHT mice (bottom). Each line represents an individual female mouse, black dots represent the day that each litter was born after introduction to the male, and the number above each line represents the number of pups per litter. (B) Number of litters per female. (C) Number of pups per female. $n=6-9$ females/group. Data were compared by 2-way ANOVA followed by Sidak's multiple comparisons test. Different letters represent significant difference. Data from B and C were compared by 2-way ANOVA. (D-G) Ovary histology. Ovary was sectioned and H\&E stained. Representative sections of ovaries from Con-no DHT, PitARKO-no DHT, Con-DHT, PitARKO-DHT. CL, corpora lutea. (H) Quantitative analysis of CL number. CLs were recorded in each group of ovaries. $n=6-19$ mice. Open bars, vehicle treated; black bars, DHT treated. Data were compared by 2-tailed Student's $t$ test. ${ }^{*} P<0.05 ;{ }^{* *} P<0.0001$.

with GnRH, and LH levels were analyzed. While all 4 groups had the same basal levels of LH (Figure 4A), following GnRH stimulation, the Con-DHT mice had a significantly attenuated LH release when compared with Con-no DHT mice. In contrast, both PitARKO-no DHT and PitARKO-DHT had levels of LH release indistinguishable from one another or Con-no DHT mice. As expected, follicular stimulating hormone (FSH) levels were not altered 20 minutes after GnRH treatment across all 4 groups (Figure 4B). Similar responses were observed ex vivo. Cultured primary pituitary cells from control ( $\mathrm{AR}^{\mathrm{f} / \mathrm{fl}} ; \mathrm{Cre}-\mathrm{e}$ mice were treated with $\mathrm{DHT}$ for 42 hours. LH and FSH secretion into the media was measured from these cells following treatment for 2 hours with GnRH. LH and FSH secretion following GnRH stimulation was reduced in a dose-responsive manner when treated with $1 \mathrm{nM}$ or $10 \mathrm{nM}$ DHT compared with no DHT treatment (Figure 4, C and D). Further, DHT did not inhibit GnRH-stimulated LH secretion in cultured pituitary cells of PitARKO mice (Supplemental Figure 3; supplemental material available online with this article; https://doi.org/10.1172/jci.insight.127817DS1). These ex vivo data suggest that DHT through AR attenuates pituitary responsiveness to GnRH. 
PitARKO abolished DHT-induced upregulation of Gem expression to potentiate $L H$ secretion in response to GnRH stimulation. To further investigate the mechanisms by which AR causes DHT-induced loss of pituitary responsiveness, we examined pituitary mRNA expression ex vivo in cultured pituitaries from control mice. We observed that Lhb mRNA levels were significantly reduced 42 hours after DHT treatment. However, Gem transcripts, inhibitors of voltage-dependent calcium $\left(\mathrm{Ca}^{2+}\right)$ channels, were upregulated following DHT treatment (Figure 4, E and F). We then examined RNA expression in vivo, harvested from pituitaries of each of the 4 groups of mice. We confirmed that $A r$ mRNA expression in pituitary was significantly lower in PitARKO mice compared with control mice with or without DHT (with normal Tsh $\beta$ mRNA; ref. 34). Lhb mRNA was not significantly different between groups, which differed from the results obtained from the ex vivo model (Figure 4, E-H).

However, in concordance with the ex vivo model, Gem was upregulated upon DHT treatment in pituitaries from Con-DHT compared with no-DHT-treated mice, while PitARKO mice did not have DHT-induced upregulation of Gem (Figure 4I).

Calcium signaling in response to GnRH stimulation was preserved in pituitaries from PitARKO mice. Inhibition of $\mathrm{Ca}^{2+}$ channels by GEM reduces $\mathrm{Ca}^{2+}$-triggered exocytosis in hormone-secreting cells; this is true for LH secretion from gonadotropes, which requires exocytosis, a process highly dependent on intracellular calcium concentration. To investigate whether $\mathrm{DHT}$ treatment inhibits $\mathrm{Ca}^{2+}$ concentration via $\mathrm{AR}$ signaling in the pituitary, we performed an intracellular calcium kinetics assay using ex vivo primary pituitary cells. We observed that DHT treatment dramatically inhibited the intracellular calcium rise in control pituitaries in response to $50 \mathrm{nM} \mathrm{GnRH}$ stimulation compared with non-DHT treated pituitaries. Pituitary cells from PitARKO mice exhibited similar intracellular calcium increases, regardless of DHT treatment following $50 \mathrm{nM}$ (Figure 5, A and B) or $10 \mathrm{nM}$ (data not shown) GnRH stimulation. These results are consistent with our observation that DHT treatment can upregulate Gem and diminish $\mathrm{LH}$ secretion in response to $\mathrm{GnRH}$ stimulation.

$A R$ binds to the promoter of Gem and increases Gem promoter expression. In order to examine if $\mathrm{AR}$ directly binds the promoter of the Gem gene to regulate transcription, we scanned a 5,000-bp region of the Gem promoter and found 2 putative consensus binding sites for AR (androgen response elements; ARE). ChIP was performed to validate AR binding to these elements. As shown in Figure 5, C-E, DHT treatment significantly increased occupancy of AR on Gem promoter binding site 1 (between -607 and -593 [tagcacaagctgctt]), and an increase (though not significant) in occupancy on Gem promoter binding site 2 (between -510 and -496 [tgggacatactgctt]) is shown. There was almost no detectable AR binding to the Gem promoter in pituitaries of PitARKO-DHT mice (Figure 5F) after immunoprecipitation. AR is mainly expressed in gonadotropes $(39,40)$. Although gonadotropes only occupy $10 \%$ of pituitary cells, PitARKO mice showed more than $50 \%$ reduction of AR expression (34). Further, DHT treatment significantly increased Gem promoter luciferase expression compared with empty vector, as shown in Figure 5G.

\section{Discussion}

Several lines of evidence indicate that pituitary responsiveness to GnRH stimulation is disrupted by testosterone $(35,41,42)$. Foecking et al., demonstrated that DHT treatment led to suppression of LH surges and basal LH secretion. When we used $10 \mathrm{nM}$ DHT ex vivo, levels used by Foecking et al. $(41,42)$, we also observed reduced basal LH secretion in control mice. Further, testosterone has been shown to suppress LH and FSH secretion independently of peripheral aromatization in both men (43-45) and women $(9,43)$. Although LH is often elevated in women with PCOS and in nonrodent animal models of PCOS, this could be due to the timing of androgen exposure, adult vs. gestational androgen exposure, and not the species differences. This indicates that, although species differences exist in the neuroendocrine regulation of ovulation, DHT reduces pituitary responsiveness to $\mathrm{GnRH}$ in both animal and human models and in humans. One explanation is that acquired androgen excess (DHT treatment in adult females) may be fundamentally different from developmental exposure to androgen excess regarding $\mathrm{LH}$ secretion, such as PCOS, which often show increased LH pulse frequency and enhanced pituitary response to GnRH stimulation (46). Women with elevated androgen levels frequently present with disrupted gonadotropin secretion (17), and confirming a role for AR, women with PCOS (or PCOS-like model in rodent) have recovered ovulation after long-term treatment with the competitive AR antagonist, flutamide $(18,47-51)$. Further, although anovulatory women with PCOS have higher basal levels of LH, LH surge is indeed inadequate. 
A

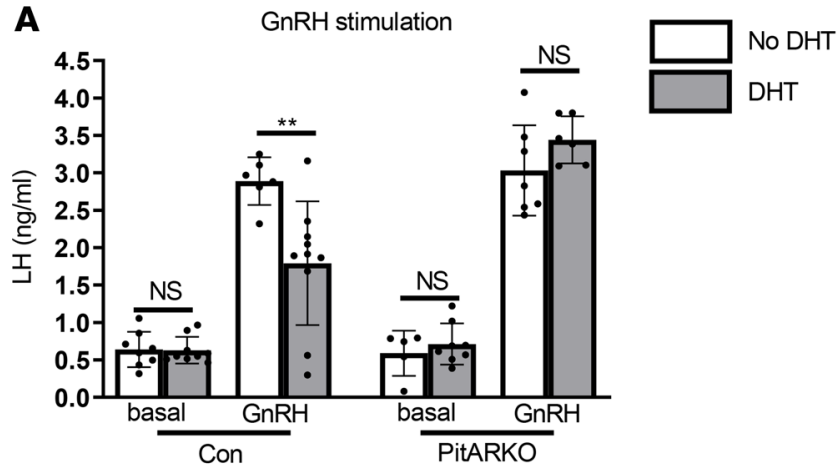

C

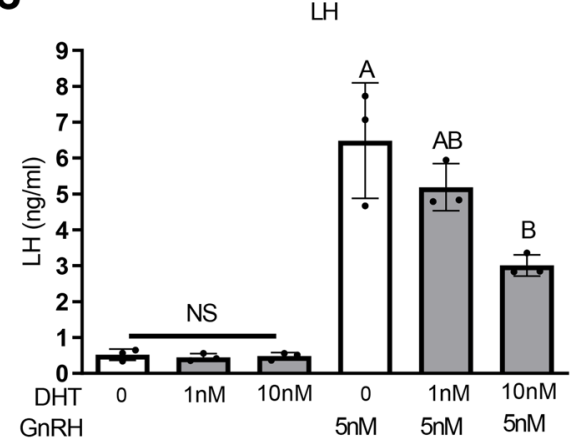

E

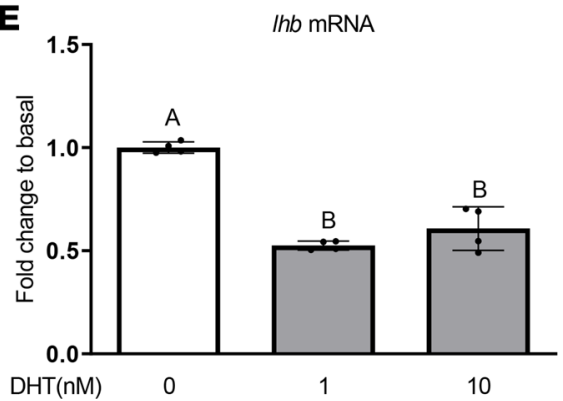

B

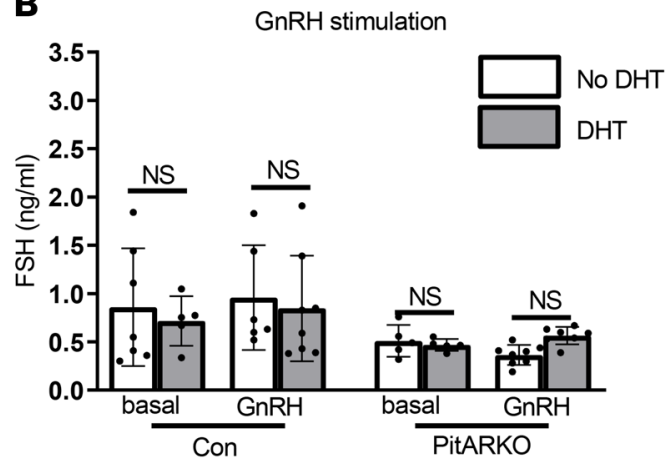

D

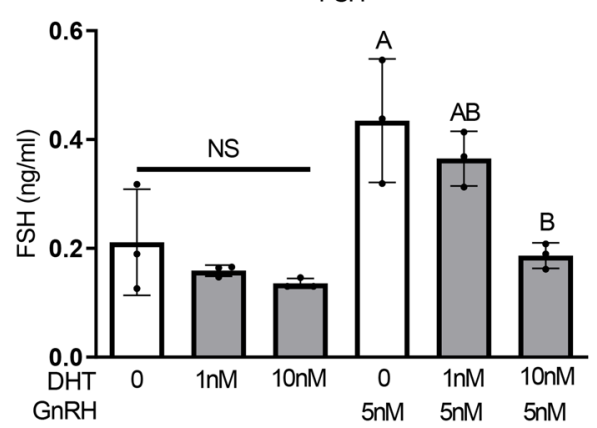

F

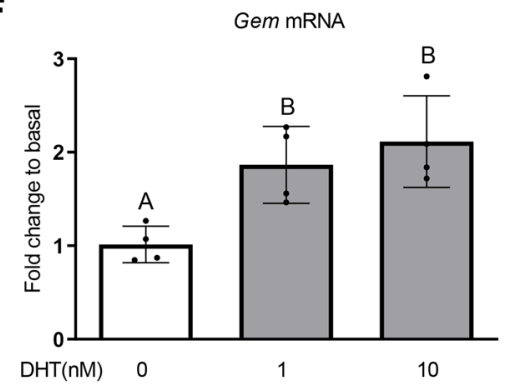

G

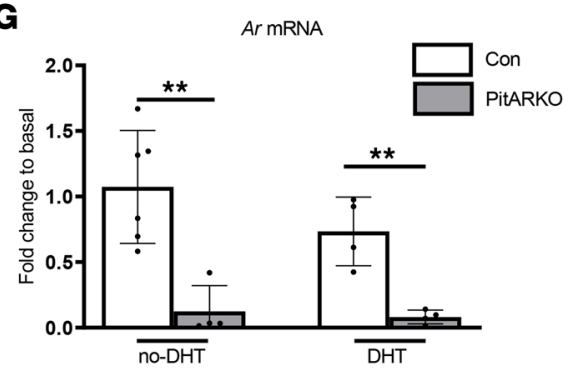

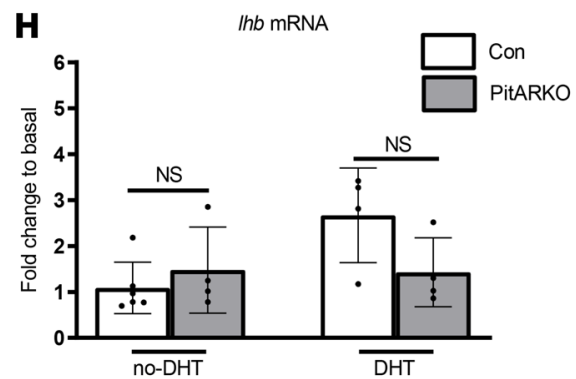

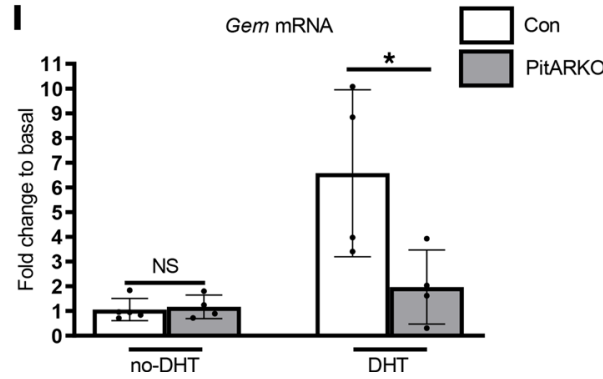

Figure 4. Pituitary hormone secretion and gene expression. (A and B) Serum LH levels (A) and FSH levels (B) before (basal) and after GnRH stimuIation in vivo. Open bars, vehicle treated; black bars, DHT treated. $n=5-10$. Data were compared by 2-tailed Student's $t$ test. (C and D) LH and FSH secretion ( 3 independent experiments) from cell culture of pooled primary pituitaries ( $\mathrm{ng} / \mathrm{ml}$ ). $n=3$ (3-5 pituitaries/pool/experiment; total number of pituitaries $=9-15$ ). Data with and without $\mathrm{GnRH}$ stimulation were compared separately by 1-way ANOVA followed by Tukey's post hoc test. (E-I) Pituitary gene expression. (E and F) Ex vivo experiments. $L h \beta$ and Gem mRNA levels after DHT treatment in primary pituitary cell culture. Open bar, vehicle treated; shaded bars, DHT treated. Data were compared by 1-way ANOVA followed by Tukey's post hoc test. $n=4$. Different letters represent significant difference. (G-I) In vivo experiments. Pituitaries were isolated from female mice at diestrus after 7-10 weeks pellet insertion. $A r$ (G); $L h \beta$ (H), Gem (I) mRNA displayed as relative fold to Con-no DHT. $n=4-6$ mice per group. Data were compared by 2-tailed Student's $t$ test. ${ }^{*} P<0.05$; ${ }^{* *} P<0.01 ;{ }^{* *} P<0.001$. 
A

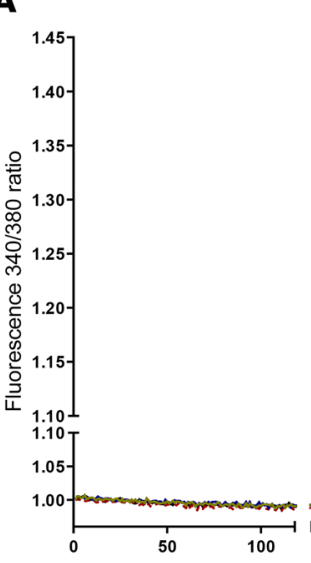

C
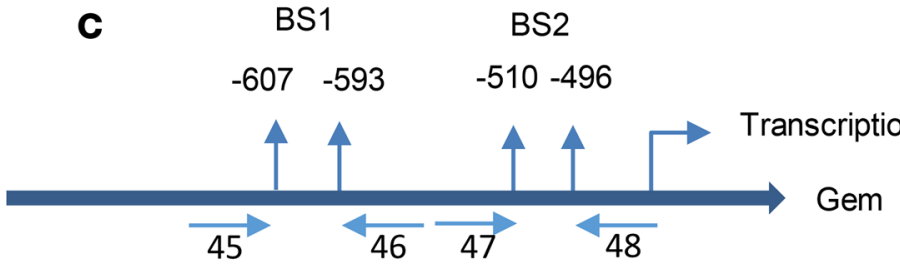

For binding site 1: tagcacaagctgctt;

2 : tgggacatactgctt

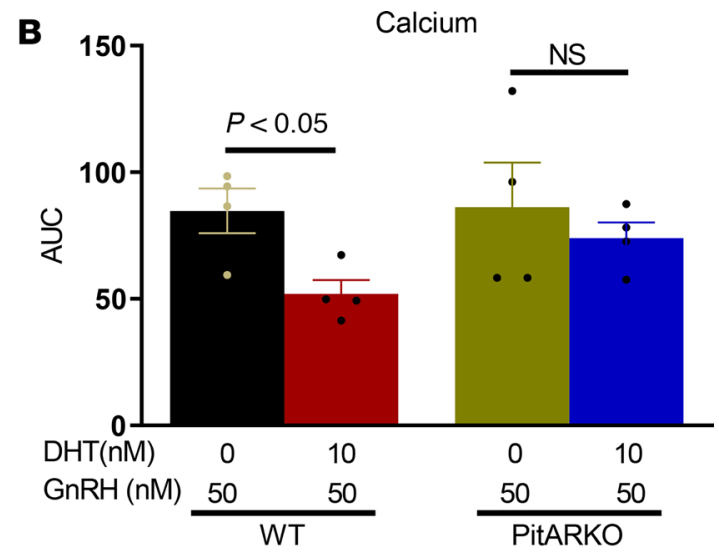

D

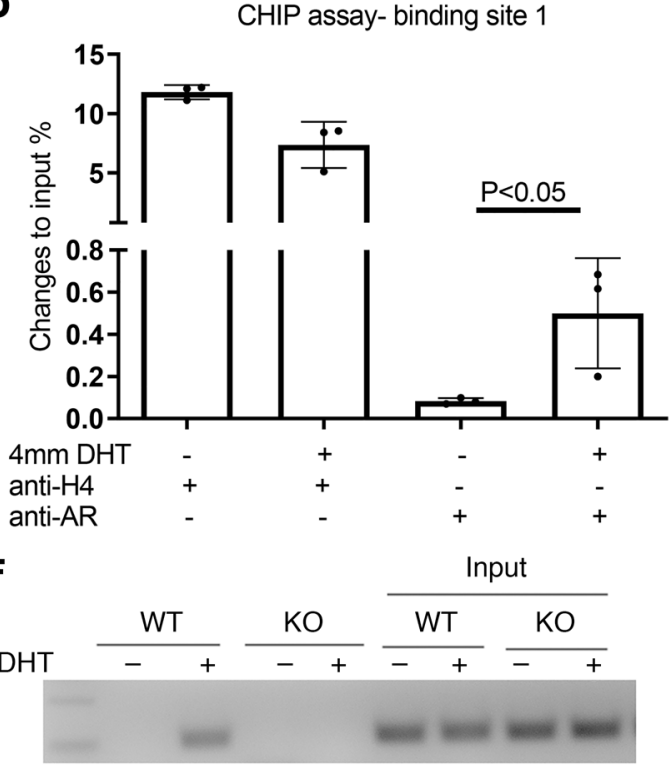

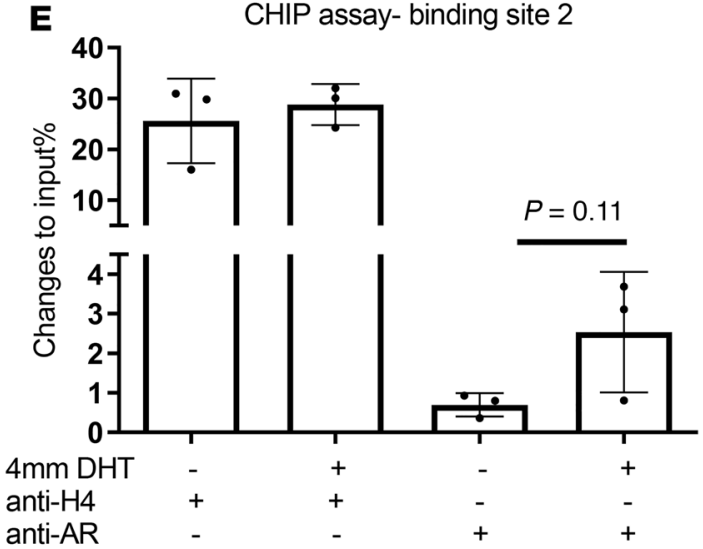

G Luc/Renilla expression of Gem promoter

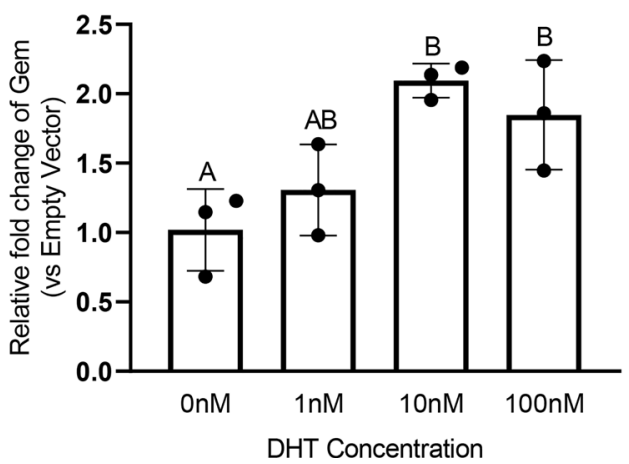

Figure 5. The effects of DHT/AR on calcium signaling and Gem promoter. (A and $\mathbf{B}$ ) Long-term DHT treatment impaired calcium signaling of pituitary cells in response to $\mathrm{GnRH}$. Pooled primary pituitary cell cultures from 3-5 mice were treated with vehicle or DHT pellet for 6 weeks (in vivo) and were incubated ex vivo with or without DHT for 42 hours before being treated with $50 \mathrm{nM} \mathrm{GnRH}$. Intracellular calcium signaling was immediately measured. Fura-2/Ca ${ }^{2+}$-specific signals were captured and 480/540 nm ratio calculated for Con- $-n R H$, PitARK-GnRH, Con-DHT-GnRH, and PitARKO-DHT-GnRH groups. $n=4$ independent experiments (total $12-20$ pituitaries). (C-F) ChIP assay. (C) Primer sets were designed flanking the AR consensus binding site (BS) position 1 (with primers 45 and 46 ) and 2 (with primers 47 and 48) in the Gem promoter. ( $\mathbf{D}$ and $\mathbf{E}$ ) ChIP assay was performed with 3-5 pooled pituitaries using antibody to AR and anti-H4. QPCR was conducted with primers flanking the Gem promoter binding sites 1 and 2 . Results were normalized to input from 3 independent ChIP experiments. $n=$ 3 (9-15 pituitaries). (F) qPCR data of AR binding to the Gem promoter with negative control (PitARKO-DHT) was shown (for primer set 45 and 46 ) in a $1.5 \%$ agarose gel as a representative example. (C) DHT increased Gem promoter expression. The Gem promoter was inserted into a luciferase reporter, and the relative fold was shown as luciferase data divided by its internal control of renilla and its own empty vector under the same treatment. $n=3$ independent experiments. Each individual experiment was conducted with 4-8 replicates. Data from B, D, and $\mathbf{E}$ were compared by 2-tailed Student's $t$ test. Data from G were compared by 1-way ANOVA followed by Tukey's post hoc test. Different letters represent significant difference. 
These females did not show any LH surges during 40 days of monitoring, and LH surges were only restored after long-term flutamide treatment (18). Collectively, clinical observations, animal models, and pharmacological studies have provided strong evidence to support the direct involvement of elevated androgen levels and its receptor (AR) in mediating actions of dysregulated female reproductive physiology (52-54). Understanding how androgen/AR affects reproduction through animal models is important for developing improved clinical interventions for treating reproductive dysfunction.

Female mice exhibit a 2-fold increase in testosterone levels compared with basal levels during the preovulatory surge (34), and this has been shown to be required for normal rates of ovulation; however, higher chronic doses of androgens reduce rates of ovulation (55). Serum androgen levels in women with PCOS or women with corrected $\mathrm{CAH}$ are approximately 2- to 3 -fold higher than in healthy women $(4,56,57)$. Because of this, and in contrast to other models, we created a model with DHT insertion, which produces serum androgen levels that are approximately 2-fold higher than in untreated mice. In general, female testosterone levels are very low; therefore, the DHT levels are also very low. The circulating DHT levels in our DHT-treated mice were 2-fold higher than untreated mice, suggesting that the pituitary in DHT-treated mice were also exposed to 2-fold higher DHT levels than untreated mice. Women with PCOS have higher levels of circulating androgens, and it is logical to expect that higher DHT levels would be found in tissues that have $5 \alpha$-reductase. The $2 x D H T$ levels in vivo may not reflect the highest levels of DHT in the pituitary. However, the $10 \mathrm{nM}$ DHT level we used ex vivo is comparable with male levels of DHT and may result in levels much higher than achieved with in vivo treatment.

Dissecting the effects of AR in the pathophysiology of elevated androgen levels is complicated and difficult using approaches that involve global AR KO. Because AR is widely expressed in different tissues and cell types, the extent to which circulating androgens impact these tissues and contribute to observed reproductive effects remains unclear. Mice with conditional AR KOs have helped to define the tissue-specific mechanism of action of androgen signaling. Females with ovarian theca ARKO (ThARKO) exhibit normal reproductive function under normal androgen conditions (22). However, ThARKO-DHT mice showed improved estrous cyclicity, ovulation, and fertility compared with Con-DHT mice, though function was not equivalent to WT or ThARKO females without DHT (22). Central nervous system AR KO mice showed normal reproductive function (our unpublished data and ref. 32) under normal androgen conditions. However, under conditions of androgen excess, these mice still exhibited aberrant cyclicity and only had a partial mitigation of DHT-induced reductions in CL $(32,58)$. Therefore, these studies do not explain the entirety of the reproductive dysfunction caused by DHT.

We previously reported that the expression of AR (both protein and mRNA) in ovaries is the same between control and PitARKO mice (34). Consistent with previous findings from our laboratory (34), in the absence of elevated androgen levels, PitARKO female mice are fertile, although they did have fewer pups per litter than controls. In the presence of high androgen levels, control mice became acyclic and infertile while PitARKO mice, like ThARKO mice, exhibited reduced acyclicity and infertility compared with Con-DHT. However, PitARKO-DHT mice had only a partial reduction in infertility, since these mice still showed reduced litters compared with both PitARKO-no DHT and Con-no DHT, as well as a reduced number of pups compared with Con-no DHT (Figure 3, B and C). PitARKO-DHT mice also showed reduced time (length) of proestus than PitARKO-no DHT, although the reduction was not significant. The time of proestrus in PitARKO-DHT mice is roughly $70 \%$ of that compared with Con-no DHT mice. Therefore, deletion of ARs in either gonadotropes or theca cells only partially mitigated the adverse effects of androgens on fertility and cyclicity. These observations demonstrate that ARs in pituitary gonadotropes play a vital role in hyperandrogenemic-induced infertility and further demonstrate that each component of the hypothalamic-pituitary-gonadal axis contributes to hyperandrogenemia-induced reproductive dysfunction $(32,34)$.

Gonadotropes located in the anterior pituitary secrete LH and FSH following GnRH stimulation. We observed that hyperandrogenemia did not affect basal LH levels in vivo. However, under hyperandrogenemic conditions, while Con-DHT mice showed reduced LH secretion in response to GnRH, PitARKO mice did not exhibit attenuated LH levels (Figure 4A). Therefore, deletion of AR in gonadotropes preserved LH secretion and pituitary responses to $\mathrm{GnRH}$ in hyperandrogenized adult mice. Although GnRH analogstimulated LH release was only modestly impaired by DHT in control mice (Figure 4A), and large amplitude LH surges are not required for ovulation in mice, we suspect that there is a threshold for LH-stimulated ovulation and that the number of eggs to be released is partially controlled by the amplitude of LH in DHT-treated mice. As previously reported (22), LH receptor expression is reduced in ovaries after DHT 
treatment; therefore, the ovary may be less responsive to LH stimulation (or less sensitive due to reduced LH receptor and or other factors). LH levels may not have reached the threshold for ovulation in Con-DHT mice compared with Con-no DHT mice. This interpretation is supported by our new data with superovulation regimen. DHT-treated mice released significantly fewer eggs compared with no DHT-treated mice after 5 units of Human chorionic gonadotropin (hCG), consistent with the conclusion that the ovary is less responsive to LH stimulation. However, DHT-treated mice with 10 units of hCG released an identical number of eggs compared with no DHT-treated mice, further demonstrating that the amplitude of LH is important for ovulation (Supplemental Figure 1).

In female mice, the gonadotropic LH surge stimulates ovulation, which is an essential process in fertility and is induced by positive feedback of estradiol on the hypothalamus and pituitary. To explore whether positive feedback regulation was disrupted by DHT in our model, as it was observed in rats (42), we used a surge induction paradigm that produced LH surge generation within 1 hour before lights off (8 p.m.) on the next day of estradiol injection. As observed before (59), LH levels at 10 a.m. and 9 p.m. were low at values similar to the basal level of mice before OVX (data not shown). Therefore, the LH levels at 10 a.m. were used as the baseline. We observed reduced LH surges in Con-DHT mice compared with Con-no DHT and PitARKO-DHT mice (Supplemental Figure 2) at 8 p.m. Given that pituitary responsiveness is a prerequisite for ovulation, DHT-induced attenuation of the LH secretion and reduced sensitivity of ovary to $\mathrm{LH}$ may explain why there were fewer CL in adult Con-DHT mice.

Androgens can act on the brain and pituitary to influence pituitary function directly or indirectly. Furthermore, there are complex positive and negative feedback loops involving the ovary at both the hypothalamus and pituitary levels that influence gonadotropin secretion. To avoid these issues and directly assess androgen effects by AR in gonadotropes, we tested androgen/AR-mediated actions in isolated pituitary cultures obtained from control mice. As shown in vivo (Figure 4A), ex vivo primary pituitary cultures confirmed that chronic androgen treatment decreased $\mathrm{LH}$ secretion in response to GnRH stimulation (Figure 4C); however, DHT did not reduce LH secretion after GnRH stimulation in PitARKO mice (Supplemental Figure 3). We observed that $L h \beta$ expression was significantly reduced in DHT-treated primary cultured pituitaries compared with vehicle-treated pituitaries ex vivo - but not in vivo. This may be due to the action of other factors in vivo that interfere with DHT effects on the $L h \beta$ expression.

$\mathrm{LH}$ secretion is controlled by $\mathrm{Ca}^{2+}$ influx $\left(\left[\mathrm{Ca}^{2+}\right]_{\mathrm{i}}\right)$ and mobilization. Spontaneous $\mathrm{Ca}^{2+}$ transients depend exclusively on $\mathrm{Ca}^{2+}$ influx through plasma membrane channels in gonadotropes, and short (10-100 ms) depolarization of cell membrane does not trigger $\mathrm{Ca}^{2+}$ release from intracellular stores. Thus, the rise in $\left[\mathrm{Ca}^{2+}\right]_{\mathrm{i}}$ in spontaneously active pituitary cells exclusively depends on voltage-dependent $\mathrm{Ca}^{2+}$ channel (VDCC) (60). We found that Gem was upregulated, while KO of AR in gonadotropes abolished DHT-induced upregulation of Gem (Figure 4I), which was first identified by RNA sequencing (data not shown). Both extra- and intracellular calcium pools participate in $\mathrm{GnRH}$-induced elevation of $\left[\mathrm{Ca}^{2+}\right]_{\mathrm{i}}$ and $\mathrm{LH}$ secretion. Blocking plasma membrane calcium channel, decreased the magnitude of the $\mathrm{Ca}^{2+}$ current and reduced the plateau phase of $\mathrm{LH}$ release by $50 \%$. Without extracellular $\mathrm{Ca}^{2+}$, the $\mathrm{GnRH}$-induced $\left[\mathrm{Ca}^{2+}\right]_{\mathrm{i}}$ peak was reduced and the plateau phase of increased $\mathrm{Ca}^{2+}$ concentration was abolished. $\mathrm{GnRH}$ stimulated calcium spikes and $\mathrm{LH}$ secretion are dependent on both the extracellular $\mathrm{Ca}^{2+}$-independent and extracellular $\mathrm{Ca}^{2+}$-dependent (influx) phase. Voltage-gated calcium entry is required for sustained agonist-induced $\mathrm{Ca}^{2+}$ spiking and $\mathrm{LH}$ secretion (61). Therefore, reduction in calcium signaling cause by DHT could be due to reduced calcium influx and or impaired calcium mobilization. The reduction of the calcium spike following GnRH stimulation in hyperandrogenized control pituitaries resulted in reduced LH release, while hyperandrogenized pituitary cells from PitARKO mice exhibited a $\mathrm{Ca}^{2+}$ spike and $\mathrm{LH}$ secretion similar to non-DHT-treated cells (Figure 5, A and B). While the PitARKO mouse model allows for isolation of effects of pituitary AR from other tissues in DHT-induced reproductive physiology, tissue specificity of androgens' effects are further confirmed by our ex vivo studies in isolated pituitary cell preparations. When we measured calcium signaling in pituitaries from mice treated with DHT for 6 weeks, differences in calcium signaling were only present after $\mathrm{GnRH}$ dosages were $10 \mathrm{nM}$ or higher $(50 \mathrm{nM})$. According to another report, differences in $\mathrm{LH}$ secretion were the greatest between vehicle- and DHT-treated cultured pituitary cells when GnRH concentrations were between $10 \mathrm{nM}$ and $100 \mathrm{nM}$ (62). Therefore, we used $50 \mathrm{nM} \mathrm{GnRH}$ in this ex vivo experiment.

The AR is a member of the nuclear hormone family of transcription factors but can also mediate androgens action via nonnuclear mechanisms. Direct interactions with the Gem promoter were demonstrated by ChIP (Figure 5, C-F), suggesting a direct transcriptional regulatory mechanism of action for 


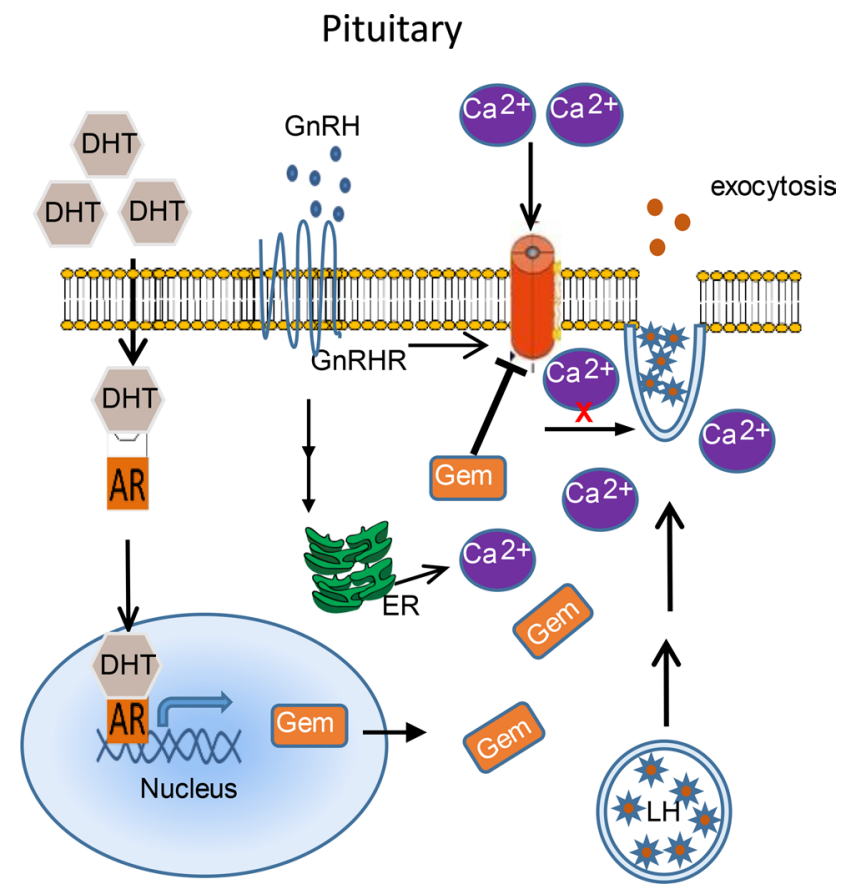

Figure 6. Working model. We hypothesize that, in the presence of androgen excess, androgen/AR binds to DHT, helping assemble active transcription machinery on the promoter of Gem and increasing Gem mRNA level. GEM inhibits calcium influx by blocking voltage-dependent calcium channel (VDCC). GnRH binds its receptor (GnRHR) to induce release of $\mathrm{LH}$ by stimulating vesicle exocytosis. Reduced cytosolic $\mathrm{Ca}^{2+}$ concentration due to increased GEM inhibits $\mathrm{Ca}^{2+}$-triggered exocytosis, reducing LH vesicle secretion during $\mathrm{GnRH}$ stimulation.

AR-mediated activation of Gem expression, which in turn may contribute to reduced calcium influx and reduced LH secretion. This finding highlights one molecular mechanism by which AR may contribute to regulation of LH secretion.

In summary, AR in gonadotropes contributes hyperandogenemia-induced reproductive dysfunction in adult mice. We propose that chronic hyperandrogenemia upregulates the VDCC inhibitor GEM, which inhibits calcium influx in response to GnRH and decreases pituitary responsiveness, thus diminishing $\mathrm{LH}$ secretion causing anovulation and infertility (Figure 6).

\section{Methods}

Generation of hyperandrogenic females. PitARKO ( $\mathrm{AR}^{\mathrm{f} / \mathrm{fl}} ; \mathrm{aGSU}$-driven $\left.\mathrm{Cre}^{+/-}\right)$mice and their controls $\left(\mathrm{Cre}^{-}\right)$ were maintained in our laboratory - the same mouse line as previously described in a mixed background (C57BL/6, CD1, and 129Sv) (34). To generate hyperandrogenic females, 2-month-old adult females had s.c. insertion of an 8-mm length pellet containing a $4 \mathrm{~mm}$ length of crystalline $5 \alpha$-dihydrotestosterone (DHT) (DHT mice: Con-DHT; PitARKO-DHT) or an empty pellet (no-DHT mice: Con-no DHT; PitARKO-no DHT). To maintain the constant level of androgen excess in DHT females, DHT or no-DHT pellets were replaced every 4 weeks during the study $(21-23,31,63)$. All experiments were conducted in female mice, and all procedures were approved by the Johns Hopkins Animal Care and Use Committee.

Assessment of estrous cyclicity and reproductive phenotypes in hyperandrogenic females. To examine whether estrous cyclicity was disrupted equally in both Con-DHT and PitARKO-DHT females, females implanted with DHT or an empty pellet were divided into 2 groups. Group 1 was assessed for estrous cyclicity by assessing vaginal smear cytology for 16 consecutive days starting 3 days after DHT treatment. The stage of the estrous cycle was determined and classified as proestrus, estrus, and metestrus/diestrus based on observed ratios of cornified epithelial, nucleated epithelial, and polymorphonuclear leukocytes, as described in ref. 64. The examiners were blinded to genotypes during all data collection.

Fertility was assessed in group 2. Fifteen days after insertion of DHT or empty pellets, females were mated with proven fertile control males in a monogamous manner. Pups and litter size from pregnant mice with and without DHT were recorded and counted for 90 days. 
Table 1. Primers for qPCR

\begin{tabular}{|c|c|c|}
\hline \multirow{2}{*}{ Ihb } & $\mathrm{F}$ & GGCCGCAGAGAATGAGTTCTG \\
\hline & $\mathrm{R}$ & CTGAGGCACAGGAGGCAAA \\
\hline \multirow{2}{*}{ Ar } & $\mathrm{F}$ & GGCGGTCCTTCACTAATGTCAACT \\
\hline & $\mathrm{R}$ & GAGACTTGTGCATGCGGTACTCAT \\
\hline \multirow{2}{*}{ Gem } & $\mathrm{F}$ & AAATCCTGCСATСAССTGTC \\
\hline & $\mathrm{R}$ & GGAAGTTCCGTCTAACAATCC \\
\hline \multirow{2}{*}{ Gem promoter } & F45 & GGTTCTGAG ATGCGCTCA T \\
\hline & R46 & GCAGCTTGTGCTAAACAGTG \\
\hline \multirow{2}{*}{ Gem promoter } & F47 & TACTCTTTCСTCCСАСТСTTC T \\
\hline & R48 & TTCСTGСTTССTСАСТTСТTATC \\
\hline \multirow{2}{*}{ Gapdh } & $\mathrm{F}$ & GGG CAT CTT GGG CTA CAC T \\
\hline & $\mathrm{R}$ & GGC ATC GAA GGT GGA AGA GT \\
\hline
\end{tabular}

In vivo GnRH stimulation and hormone assays. $\mathrm{LH}$ secretion induced by $\mathrm{GnRH}$ is commonly used to assess pituitary function. To further investigate the roles of pituitary AR in hyperandrogenemia-induced subfertility, following 6 weeks of pellet insertion, GnRH analog (catalog. L4513-1MG; MilliporeSigma) was injected s.c. at the nape of the neck at a dose of $200 \mathrm{ng} / \mathrm{kg}$ body weight (BW) per mouse at diestrus between 9-10 a.m. Whole blood was collected at 20 minutes after injection, and LH and FSH were assayed by either Luminex assay (MPTMAG-49K, MilliporeSigma) or Ultra-Sensitive Mouse and Rat LH ELISA conducted by the Ligand Assay and Analysis Core, Center for Research in Reproduction at the University of Virginia (Charlottesville, Virginia, USA).

Quantitative PCR. Pituitaries were isolated from mice at diestrus that had been treated with DHT or empty pellets for more than 6 weeks. Total RNA was extracted from the pituitaries by Trizol and reversed transcribed to cDNA with iScriptTM cDNA synthesis kit (catalog 1708891, Bio-Rad) following the manufacturer's instructions. Messenger RNA transcripts of genes ( $L h b, \mathrm{Gem}, \mathrm{Ar}$, and $\mathrm{Gapdh}$ ) and Gem promoter gene expression were measured by quantitative PCR (qPCR) using iQSYBR green reagent according to the manufacturer's protocol (Bio-Rad). Gapdh was used as the internal control. Primers are listed in Table 1.

Ex vivo primary pituitary cell culture and GnRH stimulation. Adult control or PitARKO mice without DHT insertion were sacrificed at diestrus by $\mathrm{CO}_{2}$ asphyxiation and decapitated before their pituitaries were collected. The pooled pituitaries (3-5 pituitaries) were washed with $10 \mathrm{ml}$ of 10\% FBS DMEM (Cellgro, 10-013-CV) at $2500 \mathrm{~g}$ for 5 minutes. Afterward, the pituitaries were washed with $10 \mathrm{ml} \mathrm{HBSS}$ at $2500 \mathrm{~g}$ for 5 minutes, followed by sequential digestions with collagenase (Sigma \# C0130, $2 \mathrm{ml} 1.5 \mathrm{mg} / \mathrm{ml}$ collagenase $/ 10$ pituitaries) for 2 hours at $37^{\circ} \mathrm{C}$ and in pancreatin solution (Sigma \# P3292, $4.5 \mathrm{mg} / \mathrm{ml}$ pancreatin) for 15 minutes at $37^{\circ} \mathrm{C}$. Finally, pellets were washed with 10\% FBS DMEM followed by centrifugation at $2500 \mathrm{~g}$ for 5 minutes. The primary pituitary cells were counted and placed into Matrigel-coated 24 -well (cell density is around $0.5 \times 10^{6} /$ well) or 384-well $\left(1.5 \times 10^{4}\right.$ /well) plates and incubated for 24 hours in DMEM-phenol red with 10\% FBS, $100 \mathrm{U} / \mathrm{ml}$ penicillin, and $100 \mu \mathrm{g} / \mathrm{ml}$ streptomycin (Gibco, ThermoFisher Scientific) (65-68). Cells were then cultured in $1 \mathrm{nM}$ and $10 \mathrm{nM}$ DHT or vehicle (no DHT) for 42 hours. We chose a 42-hour DHT incubation time because we observed that DHT inhibited GnRH-stimulated LH secretion in cultured primary pituitary cells after 36-48 hours of DHT treatment (data not shown). Cells were incubated with serum-free medium without phenol red for 3 hours before GnRH stimulation. GnRH was added into medium, and media were collected after 2-hour treatment. LH and FSH levels were measured by a Luminex assay or an ultrasensitive LH ELISA. Treatments were performed in triplicate or quadruplicates, and experiments were independently repeated at least 3 times.

Superovulation and egg retrieval. Female mice at diestrus after 3 weeks of DHT or no-DHT treatment were administered 5 IU or 10 IU of hCG (catalog C1063-1VL, MilliporeSigma) and were euthanized between 14-16 hours after the hCG injection. The oviducts were collected and the transparent ampulla region of each oviduct was torn open to release the cumulus-oocyte complexes (COCs) into PBS, and oocytes were counted.

Inducing LH surges with DHT and estrogen. The mouse surge protocol was adapted from refs. 41 and 59. Adult female mice were implanted with DHT for 3 days, and on the third day of DHT treatment, mice were ovariectomized (OVX) in the morning and treated with $50 \mu 1$ of $17 \beta$-estradiol $(20 \mathrm{ng} / \mu \mathrm{l}$ in sesame oil, 
Cayman Chemical) by injection. On the fourth day (the next day after OVX), blood was collected from each individual OVX mouse by mandibular vein puncture at 10 a.m., 1 hour before lights off at 8 p.m., and at 9 p.m. LH levels were measured by a Luminex assay.

Intracellular calcium kinetics assay. Mice were treated with a DHT pellet or empty pellet for at least 3 weeks. Pituitaries were isolated at diestrus; primary pituitary cells were cultured in 384-well plates and treated with or without DHT (10 nM) for 42 hours and starved for 3 hours before calcium kinetic assay. Calcium dynamics in these cells were measured immediately after treatment with $\mathrm{GnRH}(10 \mathrm{nM}$ or $50 \mathrm{nM})$ by the Johns Hopkins Chem Core Facility using a modified protocol described previously (69). Briefly, intracellular calcium signals were detected with BD Calcium Assay Kit (catalog 640176, BD Biosciences) following manufacturer's instructions. Briefly, $25 \mu \mathrm{l}$ /well of culture medium were placed in a 384 -well plate and the wells were then loaded with $25 \mu 11 \times$ dye-loading solution and incubated for 1 hour at $37^{\circ} \mathrm{C}$. GnRH agonist was added ( $5 \mu \mathrm{l} /$ well) by a FlexStation (Molecular Devices), and the kinetic curve of calcium response signals were continuously recorded before and after GnRH addition. Readings (excitation: 480nm; emission: 540 $\mathrm{nm})$ were performed at 1-second intervals. A fluorescence ratio $(480 / 540 \mathrm{~nm}$ ratio) was then calculated.

Ovarian histology. Ovaries were dissected from mice at diestrus that had been treated with pellets for more than 6 weeks. One ovary was snap frozen in liquid nitrogen for RNA or protein isolation. The other ovary was fixed in 10\% formalin phosphate buffer, and the paraffin embedded ovary was sectioned at $5 \mu \mathrm{m}$ thickness; every 10th section (total of 5 sections) was collected and stained with H\&E at the Johns Hopkins

Histology Core Facility. Ovaries were examined, and CLs were counted with a Zeiss microscope (70).

Androgen binding site prediction and validation with ChIP. The regulatory sequence analysis tools (RSAT) web server (http://rsat.ulb.ac.be/rsat/) can predict putative cis-regulatory elements and regions. The approach applies to known transcription factors, whose binding specificity is represented by position-specific scoring matrices,

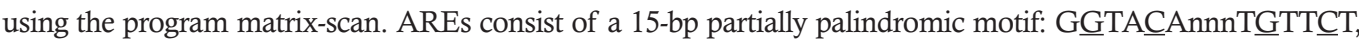
or containing the core requirement of 3 (which are underlined) out of 4 guanines contacts (71). To predict androgen receptor binding sites, we scanned between $-5,000 \mathrm{bp}$ and the transcriptional start site of the Gem gene.

To validate the putative androgen receptor binding sites of the Gem promoter, ChIP was performed. Control mice were treated with a DHT pellet or a non-DHT pellet for 3 weeks as described above. The mice were sacrificed, and pituitaries were collected and frozen immediately in liquid nitrogen. ChIP was performed with ChIP-IT Express Chromatin Immunoprecipitation Kits (catalog 53008, Active Motif) following the instructions. Anti-Androgen Receptor antibody (catalog 74272; Abcam, Cambridge, MA) and Anti-histone H4 antibody (catalog sc-25260; Santa Cruz, Dallas, TX) were used as a positive control in immunoprecipitation. Pituitaries isolated from PitARKO-DHT were used as negative control. qPCR was performed with qPCR kit (catalog 170-8882, iQTM SYBR Green Supermix, Bio-Rad) following the instructions. Primers are listed in Table 1.

Androgen regulation of Gem promoter luciferase expression. To analyze whether DHT directly regulates gem expression, the Gem promoter (3006 bp of length from the transcription start site) encompassing the two predicted AR binding sites was inserted into PA3-LUC firefly luciferase reporter construct (Gem-LUC). TK-Renilla was used as an internal control. WT AR plasmid (72) and Gem-LUC were cotransfected into 96-well H2.35 cell lines to test the Gem promoter activity. DHT was applied to the cells at the doses of 0,1 , 10 , or $100 \mathrm{nM}$. Empty vector PA3-LUC (replaced Gem-LUC) with the same treatment was used as a basal control. The fold change is expressed as the relative firefly/renilla luciferase values vs. its empty vector value (basal control). Three independent experiments were conducted - each one with 4-8 replicates.

Statistics. Data were analyzed by an unpaired Student's $t$ test (2-tailed), by 1-way ANOVA followed by Tukey's post hoc test, or 2-way ANOVA followed by Sidak's multiple comparisons test (specifically addressed in figure legends) accordingly using GraphPad Prism (GraphPad Software). All results are expressed as means \pm SEM. Statistical significance was defined as $P<0.05$.

Statistics. All procedures were approved by the Johns Hopkins Animal Care and Use Committee.

\section{Author contributions}

ZW and SW contributed to the experimental design, conducting the experiments, and writing and editing the manuscript. MF, OA, YM, MS, and PX contributed to performing some of the experiments, analyzing the corresponding data, and writing part of the manuscript. JS, RA, and AW contributed to the experimental design and reviewing and editing the manuscript. 


\section{Acknowledgments}

We thank Ursula Kaiser (Harvard Medical School) for sharing the pituitary primary cell culture protocols. This work was supported by the NIH (grant R00-HD068130 to SW) and the Baltimore Diabetes Research Center: Pilots and Feasibility Grant (to SW).

Address correspondence to: Sheng Wu, 600 North Wolfe Street, CMSC-406, Baltimore, Maryland 21287, USA. Phone: 410.502.7573; Email: swu24@jhmi.edu.

1. Lizneva D, Suturina L, Walker W, Brakta S, Gavrilova-Jordan L, Azziz R. Criteria, prevalence, and phenotypes of polycystic ovary syndrome. Fertil Steril. 2016;106(1):6-15.

2. Goodarzi MO, Carmina E, Azziz R. DHEA, DHEAS and PCOS. J Steroid Biochem Mol Biol. 2015;145:213-225.

3. Carmina E, et al. Non-classic congenital adrenal hyperplasia due to 21-hydroxylase deficiency revisited: an update with a special focus on adolescent and adult women. Hum Reprod Update. 2017;23(5):580-599.

4. van Houten EL, Kramer P, McLuskey A, Karels B, Themmen AP, Visser JA. Reproductive and metabolic phenotype of a mouse model of PCOS. Endocrinology. 2012;153(6):2861-2869.

5. Ambroziak U, et al. The diagnosis of nonclassic congenital adrenal hyperplasia due to 21-hydroxylase deficiency, based on serum basal or post-ACTH stimulation 17-hydroxyprogesterone, can lead to false-positive diagnosis. Clin Endocrinol (Oxf). 2016;84(1):23-29.

6. Chan KJ, Liang JJ, Jolly D, Weinand JD, Safer JD. Exogenous Testosterone Does Not Induce or Exacerbate the Metabolic Features Associated with PCOS Among Transgender Men. Endocr Pract. 2018;24(6):565-572.

7. Caanen MR, et al. Antimüllerian hormone levels decrease in female-to-male transsexuals using testosterone as cross-sex therapy. Fertil Steril. 2015;103(5):1340-1345.

8. Pache TD, et al. Ovarian morphology in long-term androgen-treated female to male transsexuals. A human model for the study of polycystic ovarian syndrome? Histopathology. 1991;19(5):445-452.

9. Spinder T, et al. The effects of long term testosterone administration on pulsatile luteinizing hormone secretion and on ovarian histology in eugonadal female to male transsexual subjects. J Clin Endocrinol Metab. 1989;69(1):151-157.

10. Bosinski HA, et al. A higher rate of hyperandrogenic disorders in female-to-male transsexuals. Psychoneuroendocrinology. 1997;22(5):361-380.

11. Diamanti-Kandarakis E, et al. Endocrine-disrupting chemicals: an Endocrine Society scientific statement. Endocr Rev. 2009;30(4):293-342

12. Caldwell AS, et al. Characterization of reproductive, metabolic, and endocrine features of polycystic ovary syndrome in female hyperandrogenic mouse models. Endocrinology. 2014;155(8):3146-3159.

13. Kauffman AS, et al. A Novel Letrozole Model Recapitulates Both the Reproductive and Metabolic Phenotypes of Polycystic Ovary Syndrome in Female Mice. Biol Reprod. 2015;93(3):69.

14. Kelley ST, Skarra DV, Rivera AJ, Thackray VG. The Gut Microbiome Is Altered in a Letrozole-Induced Mouse Model of Polycystic Ovary Syndrome. PLoS ONE. 2016;11(1):e0146509.

15. Kafali H, Iriadam M, Ozardali I, Demir N. Letrozole-induced polycystic ovaries in the rat: a new model for cystic ovarian disease. Arch Med Res. 2004;35(2):103-108.

16. Cardoso RC, Puttabyatappa M, Padmanabhan V. Steroidogenic versus Metabolic Programming of Reproductive Neuroendocrine, Ovarian and Metabolic Dysfunctions. Neuroendocrinology. 2015;102(3):226-237.

17. Dumesic DA, Abbott DH, Padmanabhan V. Polycystic ovary syndrome and its developmental origins. Rev Endocr Metab Disord. 2007;8(2):127-141.

18. De Leo V, Lanzetta D, D'Antona D, la Marca A, Morgante G. Hormonal effects of flutamide in young women with polycystic ovary syndrome. J Clin Endocrinol Metab. 1998;83(1):99-102.

19. Brothers KJ, et al. Rescue of obesity-induced infertility in female mice due to a pituitary-specific knockout of the insulin receptor. Cell Metab. 2010;12(3):295-305.

20. Delemarre-van de Waal HA, van Coeverden SC, Engelbregt MT. Factors affecting onset of puberty. Horm Res. 2002;57 Suppl 2:15-18

21. Andrisse S, et al. Low-Dose Dihydrotestosterone Drives Metabolic Dysfunction via Cytosolic and Nuclear Hepatic Androgen Receptor Mechanisms. Endocrinology. 2017;158(3):531-544.

22. Ma Y, et al. Androgen Receptor in the Ovary Theca Cells Plays a Critical Role in Androgen-Induced Reproductive Dysfunction Endocrinology. 2017;158(1):98-108

23. Xue P, et al. A Hyperandrogenic Mouse Model to Study Polycystic Ovary Syndrome. J Vis Exp. 2018;(140).

24. Silfen ME, et al. Early endocrine, metabolic, and sonographic characteristics of polycystic ovary syndrome (PCOS): comparison between nonobese and obese adolescents. J Clin Endocrinol Metab. 2003;88(10):4682-4688.

25. Fassnacht M, Schlenz N, Schneider SB, Wudy SA, Allolio B, Arlt W. Beyond adrenal and ovarian androgen generation: Increased peripheral 5 alpha-reductase activity in women with polycystic ovary syndrome. J Clin Endocrinol Metab. 2003;88(6):2760-2766.

26. Eden JA, Jones J, Carter GD, Alaghband-Zadeh J. Follicular fluid concentrations of insulin-like growth factor 1, epidermal growth factor, transforming growth factor-alpha and sex-steroids in volume matched normal and polycystic human follicles. Clin Endocrinol (Oxf). 1990;32(4):395-405.

27. Qu F, et al. Altered aquaporin expression in women with polycystic ovary syndrome: hyperandrogenism in follicular fluid inhibits aquaporin-9 in granulosa cells through the phosphatidylinositol 3-kinase pathway. Hum Reprod. 2010;25(6):1441-1450.

28. Nakamura Y, Yoshimura Y, Kamei K, Izumi Y, Sawada T, Iizuka R. Androgen production by human isolated components of normal and polycystic ovaries in vitro. Endocrinol Jpn. 1982;29(3):307-317.

29. Wickenheisser JK, Nelson-DeGrave VL, Hendricks KL, Legro RS, Strauss JF, McAllister JM. Retinoids and retinol differentially 
regulate steroid biosynthesis in ovarian theca cells isolated from normal cycling women and women with polycystic ovary syndrome. J Clin Endocrinol Metab. 2005;90(8):4858-4865.

30. de Resende LO, et al. [Concentration of steroid hormones in the follicular fluid of mature and immature ovarian follicles of patients with polycystic ovary syndrome submitted to in vitro fertilization]. Rev Bras Ginecol Obstet. 2010;32(9):447-453.

31. Andrisse S, Billings K, Xue P, Wu S. Insulin signaling displayed a differential tissue-specific response to low-dose dihydrotestosterone in female mice. Am J Physiol Endocrinol Metab. 2018;314(4):E353-E365.

32. Caldwell ASL, et al. Neuroendocrine androgen action is a key extraovarian mediator in the development of polycystic ovary syndrome. Proc Natl Acad Sci USA. 2017;114(16):E3334-E3343.

33. Silva MS, Prescott M, Campbell RE. Ontogeny and reversal of brain circuit abnormalities in a preclinical model of PCOS. JCI Insight. 2018;3(7):99405

34. Wu S, et al. Conditional knockout of the androgen receptor in gonadotropes reveals crucial roles for androgen in gonadotropin synthesis and surge in female mice. Mol Endocrinol. 2014;28(10):1670-1681.

35. Kamel F, Krey LC. Gonadal steroid modulation of LHRH-stimulated LH secretion by pituitary cell cultures. Mol Cell Endocrinol. 1982;26(1-2):151-164

36. Béguin $\mathrm{P}$, et al. Regulation of $\mathrm{Ca} 2+$ channel expression at the cell surface by the small G-protein kir/Gem. Nature 2001;411(6838):701-706.

37. Melamed P, et al. Gonadotrophin-releasing hormone signalling downstream of calmodulin. J Neuroendocrinol. 2012;24(12):1463-1475.

38. Correll RN, Pang C, Niedowicz DM, Finlin BS, Andres DA. The RGK family of GTP-binding proteins: regulators of voltage-dependent calcium channels and cytoskeleton remodeling. Cell Signal. 2008;20(2):292-300.

39. Stefaneanu L. Pituitary Sex Steroid Receptors: Localization and Function. Endocr Pathol. 1997;8(2):91-108.

40. Yuan X, He Y, Liu J, Luo H, Zhang J, Cui S. Expression of androgen receptor and its co-localization with estrogen receptor-alpha in the developing pituitary gland of sheep fetus. Histochem Cell Biol. 2007;127(4):423-432.

41. Foecking EM, Levine JE. Effects of experimental hyperandrogenemia on the female rat reproductive axis: suppression of progesterone-receptor messenger RNA expression in the brain and blockade of luteinizing hormone surges. Gend Med. 2005;2(3):155-165.

42. Foecking EM, McDevitt MA, Acosta-Martínez M, Horton TH, Levine JE. Neuroendocrine consequences of androgen excess in female rodents. Horm Behav. 2008;53(5):673-692.

43. Iwata K, Kunimura Y, Matsumoto K, Ozawa H. Effect of androgen on Kiss1 expression and luteinizing hormone release in female rats. $J$ Endocrinol. 2017;233(3):281-292.

44. Santen RJ. Is aromatization of testosterone to estradiol required for inhibition of luteinizing hormone secretion in men? J Clin Invest. 1975;56(6):1555-1563.

45. Marynick SP, Loriaux DL, Sherins RJ, Pita JC, Lipsett MB. Evidence that testosterone can suppress pituitary gonadotropin secretion independently of peripheral aromatization. J Clin Endocrinol Metab. 1979;49(3):396-398.

46. Moore AM, Campbell RE. Polycystic ovary syndrome: Understanding the role of the brain. Front Neuroendocrinol. 2017;46:1-14

47. Eagleson CA, et al. Polycystic ovarian syndrome: evidence that flutamide restores sensitivity of the gonadotropin-releasing hormone pulse generator to inhibition by estradiol and progesterone. J Clin Endocrinol Metab. 2000;85(11):4047-4052.

48. Goodman NF, et al. American Association of Clinical Endocrinologists, American College of Endocrinology, and Androgen Excess and PCOS Society Disease State Clinical Review: Guide to the Best Practices in the Evaluation and Treatment of Polycistic Ovary Syndrome - Part 2. Endocr Pract. 2015;21(12):1415-1426.

49. Diamanti-Kandarakis E, Mitrakou A, Raptis S, Tolis G, Duleba AJ. The effect of a pure antiandrogen receptor blocker, flutamide, on the lipid profile in the polycystic ovary syndrome. J Clin Endocrinol Metab. 1998;83(8):2699-2705.

50. Blank SK, McCartney CR, Marshall JC. The origins and sequelae of abnormal neuroendocrine function in polycystic ovary syndrome. Hum Reprod Update. 2006;12(4):351-361.

51. Ryan GE, Malik S, Mellon PL. Antiandrogen Treatment Ameliorates Reproductive and Metabolic Phenotypes in the Letrozole-Induced Mouse Model of PCOS. Endocrinology. 2018;159(4):1734-1747.

52. Goodarzi MO, Dumesic DA, Chazenbalk G, Azziz R. Polycystic ovary syndrome: etiology, pathogenesis and diagnosis. Nat Rev Endocrinol. 2011;7(4):219-231.

53. Shorakae S, Boyle J, Teede H. Polycystic ovary syndrome: a common hormonal condition with major metabolic sequelae that physicians should know about. Intern Med J. 2014;44(8):720-726.

54. Walters KA. Role of androgens in normal and pathological ovarian function. Reproduction. 2015;149(4):R193-R218.

55. Yasin M, Dalkin AC, Haisenleder DJ, Marshall JC. Testosterone is required for gonadotropin-releasing hormone stimulation of luteinizing hormone-beta messenger ribonucleic acid expression in female rats. Endocrinology. 1996;137(4):1265-1271.

56. Silfen ME, et al. Early endocrine, metabolic, and sonographic characteristics of polycystic ovary syndrome (PCOS): comparison between nonobese and obese adolescents. J Clin Endocrinol Metab. 2003;88(10):4682-4688.

57. Fassnacht M, Schlenz N, Schneider SB, Wudy SA, Allolio B, Arlt W. Beyond adrenal and ovarian androgen generation: Increased peripheral 5 alpha-reductase activity in women with polycystic ovary syndrome. J Clin Endocrinol Metab. 2003;88(6):2760-2766

58. Caldwell AS, et al. Haplosufficient genomic androgen receptor signaling is adequate to protect female mice from induction of polycystic ovary syndrome features by prenatal hyperandrogenization. Endocrinology. 2015;156(4):1441-1452.

59. Wu S, Divall S, Hoffman GE, Le WW, Wagner KU, Wolfe A. Jak2 is necessary for neuroendocrine control of female reproduction. J Neurosci. 2011;31(1):184-192.

60. Stojilkovic SS. Pituitary cell type-specific electrical activity, calcium signaling and secretion. Biol Res. 2006;39(3):403-423.

61. Stojilković SS, et al. Generation and amplification of the cytosolic calcium signal during secretory responses to gonadotropin-releasing hormone. New Biol. 1990;2(3):272-283.

62. Ortmann O, Tomic M, Weiss JM, Diedrich K, Stojilkovic SS. Dual action of androgen on calcium signaling and luteinizing hormone secretion in pituitary gonadotrophs. Cell Calcium. 1998;24(3):223-231.

63. Wang Z, Shen M, Xue P, DiVall SA, Segars J, Wu S. Female Offspring From Chronic Hyperandrogenemic Dams Exhibit 
Delayed Puberty and Impaired Ovarian Reserve. Endocrinology. 2018;159(2):1242-1252.

64. Nelson JF, Felicio LS, Randall PK, Sims C, Finch CE. A longitudinal study of estrous cyclicity in aging C57BL/6J mice: I. Cycle frequency, length and vaginal cytology. Biol Reprod. 1982;27(2):327-339.

65. Krey LC, Kamel F. Progesterone modulation of gonadotropin secretion by dispersed rat pituitary cells in culture. I. Basal and gonadotropin-releasing hormone-stimulated luteinizing hormone release. Mol Cell Endocrinol. 1990;68(2-3):85-94.

66. Savulescu D, et al. Gonadotropin-releasing hormone-regulated prohibitin mediates apoptosis of the gonadotrope cells. Mol Endocrinol. 2013;27(11):1856-1870.

67. Wen S, et al. Functional characterization of genetically labeled gonadotropes. Endocrinology. 2008;149(6):2701-2711.

68. Do MH, Santos SJ, Lawson MA. GNRH induces the unfolded protein response in the LbetaT2 pituitary gonadotrope cell line. Mol Endocrinol. 2009;23(1):100-112.

69. Song WJ, Mondal P, Li Y, Lee SE, Hussain MA. Pancreatic $\beta$-cell response to increased metabolic demand and to pharmacologic secretagogues requires EPAC2A. Diabetes. 2013;62(8):2796-2807.

70. Wu S, et al. Obesity-induced infertility and hyperandrogenism are corrected by deletion of the insulin receptor in the ovarian theca cell. Diabetes. 2014;63(4):1270-1282.

71. Claessens F, et al. Selective DNA binding by the androgen receptor as a mechanism for hormone-specific gene regulation J Steroid Biochem Mol Biol. 2001;76(1-5):23-30.

72. Yu IC, et al. Neuronal androgen receptor regulates insulin sensitivity via suppression of hypothalamic NF- $\mathrm{kB}-\mathrm{mediated} \mathrm{PTP} 1 \mathrm{~B}$ expression. Diabetes. 2013;62(2):411-423. 